\section{Research Square}

Preprints are preliminary reports that have not undergone peer review.

They should not be considered conclusive, used to inform clinical practice, or referenced by the media as validated information.

\title{
Longitudinal variations of noontime thermospheric winds in response to IMF Bz temporal oscillations: broken mean circulation and standing feature
}

Kedeng Zhang ( $\boldsymbol{\sim}$ Ninghe_zkd@whu.edu.cn )

Wuhan University https://orcid.org/0000-0003-2423-7419

Hui Wang

Wuhan University https://orcid.org/0000-0001-8459-5213

Wenbin Wang

High Altitude Observatory, National Center for Atmospheric Research

Jing Liu

High Altitude Observatory, National Center for Atmospheric Research

Jie Gao

Wuhan University

Research article

Keywords: Periodic oscillation of IMF Bz, Modeling and forecasting, thermospheric winds, Standing feature, longitudinal differences

Posted Date: October 26th, 2020

DOI: https://doi.org/10.21203/rs.3.rs-46709/v3

License: (c) (i) This work is licensed under a Creative Commons Attribution 4.0 International License.

Read Full License 


\section{Abstract}

By using the coupled magnetosphere-thermosphere-ionosphere model, we explore the longitudinal/UT differences of the dayside neutral wind in response to the 60 min periodic oscillation of the interplanetary magnetic field (IMF) Bz. The southward propagation of the traveling atmospheric disturbances (TADs) in meridional wind stands at about $20^{\circ} \mathrm{MLat}$, which is related to the geomagnetic field configuration, neutral temperature, and electron density changes. The meridional wind travels continuously from high to low latitude in the western southern hemisphere, while they are broken into pieces in the eastern southern hemisphere. The broken mean circulation that is a combined effect of TADs and simultaneous responses of the meridional winds driven by oscillating solar wind conditions is induced by the stronger roles of the ion drag than the pressure gradient. Note here that the mean circulation is the background meridional winds in the base case. The ion drag shows obvious longitudinal differences associated with the penetration of the ionospheric electric field during the oscillation of IMF Bz.

\section{Introduction}

The energy carried by the solar wind can be fully deposited into the Earth's upper thermosphere at high latitudes, and produce longitudinally extended waves (Bruinsma et al., 2007, 2009; Liu et al., 2018b). These waves then propagate away from the source region to other regions of the coupled lonosphereThermosphere (IT) system. These waves are named as traveling atmospheric disturbances (TADs), which are a key factor in understanding the variability of the IT system. Exploring the possible mechanisms of TADs is critical in the modeling and forecasting of near-Earth upper atmosphere environment.

In the past decades, TADs during disturbed periods have attracted much attention (e.g., Bruinsma \& Forbes, 2007; Liu and Lühr, 2005; Liu et al., 2010, 2014, 2018b; Oliveira et al., 2017; Otsuka et al., 2004; Shiokawa et al., 2003; Sutton et al., 2009; Thome et al., 1964; Zhang et al., 2019). Previous studies have reported that the storm time energetic particle precipitation and Joule heating (Rodríguez-Zuluaga et al., 2016), the gravity waves (Liu et al., 2014), and the sunset terminator (Beer, 1973) are critical in the generation of TADs. The storm time energy deposition can significantly increase the neutral temperature at high latitudes, changing the global circulation and triggering the TADs via the pressure gradient force. The upward propagating gravity waves, which are ubiquitous in the mesosphere and lower thermosphere, and atmospheric waves that are associated with the sunset terminator, can deposite energy and momentum at higher altitudes. This energy deposition also plays a role in the neutral temperature changes in the thermosphere, and cause TADs.

As reported by Dungey (1961), the geomagnetic storms can be induced by the interaction between the IMF Bz in southward and the geomagnetic field. During disturbed periods, a large amount of energy and momentum carried by the solar wind is deposited into the Earth's upper atmosphere, changing the global circulation and producing TADs. TADs have been studied using meridional winds, neutral temperature, composition (O/N2), and air mass density data (e.g., Bruinsma and Forbes, 2007; Bruinsma et al., 2009; Fujiwara et al., 2006; Lei et al., 2008). Typically, TADs propagate with velocities of 400-1000 (100-300) 
$\mathrm{m} / \mathrm{s}$, periods of 0.5-3 (0.25-1) hour, and wavelength of thousands (hundreds) of kilometers in large-scales (medium-scales) (e.g., Bruinsma and Forbes, 2009; Hocke and Schlegel, 1996).

Liu and Lühr (2005) found that during storm times the enhancement of the thermospheric air mass density in the noontime showed two different features (see the upper panel of Figure 3 in Liu and Lühr, 2005). One was the enhancement in the density at $0^{\circ} \sim 40^{\circ}$ geomagnetic latitudes (MLat), which originated from the TAD propagating from the auroral region to low latitudes at around 20 UT on 30 October 2003. The other was the almost instant enhancement in the density at aurora and middle latitudes at about 20:00 UT on 30 October 2003. These two features overlapped at 20:00 UT and 40 MLat, forming broken mean circulation. This broken feature and its possible mechanisms have rarely been studied in the literature, which is one of the focus of the study.

Another interesting topic is raised by Sharma et al. (2011). They reported a longitudinal variation of the

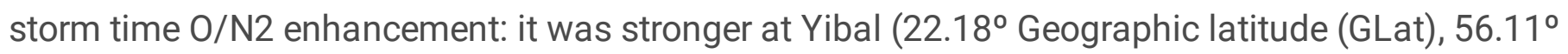
Geographic longitude (GLon)) than at Kunming $\left(25.03^{\circ} \mathrm{GLat}, 102.79^{\circ} \mathrm{GLon}\right)$ and Udaipur $\left(24.67^{\circ} \mathrm{GLat}\right.$, $\left.74.69^{\circ} \mathrm{GLon}\right)$. This longitudinal variation was attributed to the air upwelling due to the equatorward meridional wind (Sharma et al., 2011). The question is then whether TADs in the meridional wind also show notable longitudinal variations? Based on observations from all-sky airglow imagers, Otsuka et al. (2004) investigated the geomagnetic conjugacy of the medium-scale traveling ionospheric disturbances (TID). The conjugacy structures came from the polarization electric field that maps along geomagnetic field lines and moves the $\mathrm{F}$ region plasma upward/downward, producing the mirrored structures of plasma perturbations in the Northern and Southern Hemispheres. TID can be treated as the ionospheric counterpart of TAD with phase and time delay compared to TAD. Thus, the hemispheric conjugacy of the TAD is worthy of investigation.

While the TADs in thermospheric winds during storm time have been established in the literature, the exact longitudinal and hemispheric changes of the meridional wind responses to temporal oscillations of IMF Bz is still poorly understood, due to the fact that the thermospheric winds are balanced among many drivers (i.e., pressure gradient, ion drag, Coriolis). The thermospheric winds are important factors in the understanding of changes in the ionosphere-thermosphere coupling system. In addition, the periodic oscillations of IMF Bz are a common phenomenon seen in the solar wind, which can produce periodic oscillations in the energy and momentum deposition in the upper atmosphere and TADs (e.g., Liu et al., 2018a; Zhang et al., 2019). Taking the abovementioned into consideration, the present work is to study the longitudinal and hemispheric patterns of the meridional wind changes at a fixed local time, which show some interesting signals of the broken mean circulation, standing feature, and the related longitudinal and hemispheric variations during the period of the oscillating IMF Bz. Furthermore, these thermospheric wind changes have not caught so much attention in the literature. The possible drivers for the noontime wind changes are revealed, including the possible effects of the geomagnetic topology. Electron density, plasma motion, and neutral temperature changes are also examined.

\section{Methods}




\section{CHAMP Data}

The orbit of the CHAllenging Minisatellite Payload (CHAMP) satellite was near-polar ( $87.3^{\circ}$ inclination) (Reigber et al., 2002). The orbital period of CHAMP is about $93 \mathrm{~min}$. The initial orbital altitude was 460 $\mathrm{km}$ in 2000, then decreased to about $400 \mathrm{~km}$ in 2005 and about $300 \mathrm{~km}$ in 2008 due to atmospheric drag. The neutral air density data is deduced from the measurements by the accelerometer on board of the CHAMP (Sutton et al., 2007). In this work, the observed mass density data at geographic latitudes of $-60^{\circ} \sim 60^{\circ}$ are processed according to the orbit-by-orbit method (Häusler et al., 2007).

\section{CMIT Model}

The Coupled Magnetosphere lonosphere Thermosphere (CMIT) model consists of two parts. One is the Thermosphere lonosphere Electrodynamic General Circulation Model (TIEGCM) v1.95, the other is the Lyon-Fedder-Mobarry (LFM) global magnetohydrodynamic magnetospheric model (Wang et al., 2004; Wiltberger et al., 2004). When investigating the coupling in the MIT system, the model outputs have achieved good agreements with observations and other model outputs, confirming the reliability and stability of CMIT (e.g., Cnossen \& Richmond, 2013; Liu et al., 2018a; Wang et al., 2008). The TIEGCM is a three-dimensional, time-dependent model of the coupled IT system. The drivers of TIEGCM are shown as follow: the particle precipitation and high-latitude electric fields (Heelis et al., 1982), solar extreme ultraviolet and ultraviolet spectral fluxes (Richards et al., 1994), the upward-propagating atmospheric tides (Hagan \& Forbes., 2002, 2003). Note here that the atmospheric tides, including migrating and nonmigrating tides, are either specified by the global scale wave model or derived from the Sounding of the Atmosphere using Broadband Emission Radiometry (SABER) and TIDI observations. The TIEGCM has a horizontal resolution of $2.5^{\circ} \mathrm{GLat} \times 2.5^{\circ} \mathrm{GLon}$, and a vertical resolution of quarter-scale height with 57 levels. The model extends from $\sim 97 \mathrm{~km}$ to $\sim 600 \mathrm{~km}$ in the vertical direction, with the upper boundary depending on the solar activity. As revealed by Lyon et al. (2004), the drivers of LFM Magnetosphere model are the solar wind and IMF data, and the boundary of LFM extends from - 300 RE to 2RE. The RE is the Earth's radius. In the coupled MIT system, the modeled ionospheric conductivity from TIEGCM is imposed into the LFM, and the simulated auroral particle precipitation and high-latitude electric fields from the LFM are used to drive the TIEGCM.

In this study, the changes in the IT system due to the effects of IMF Bz oscillation are explored by performing two CMIT simulations. One is the 60 -min case that $\mathrm{Bz}$ varies with a maximum amplitude of $10 \mathrm{nT}$ (from -10 nT to $10 \mathrm{nT}$ ) and a sine function of a period of $60 \mathrm{~min}$, the other is the CMIT base run with a constant Bz value of $0 \mathrm{nT}$. The hemispheric power, joule heating, and partial precipitation oscillate as well (Figures not shown). The auroral oval (size and locations) change in a similar way to the particle precipitation. The electric field penetration also oscillates with a similar amplitude as observed (Figures not shown, Wei et al., 2008). As reported by Wei et al. (2008), the penetrating electric field oscillates with the observed IMF Bz. The maximum amplitude of the penetrating electric fields at Jicamarca $\left(11.9^{\circ} \mathrm{S}\right.$ GLAT, $76.8^{\circ} \mathrm{W}$ GLON) is $\sim 1 \mathrm{mv} / \mathrm{m}$ in their case. In our simulations, the maximum PPEF is $\sim 3 \mathrm{mv} / \mathrm{m}$ (Figure not shown), which might be overestimated (Merkin et al., 2005; Wang et al., 2008). As shown in 
the previous work of Zhang et al. (2019), the disturbed wind in the oscillation period of 60 minutes in IMF $\mathrm{Bz}$ is strongest when compared to the other two cases with an oscillation period of 10 and 30 minutes. Thus, in the present work, we will focus on the 60-min case. In addition, the other input solar wind conditions for CMIT are solar wind density $\left(5 \mathrm{~cm}^{-3}\right)$, velocity $(400 \mathrm{~km} / \mathrm{s})$, IMF Bx and By (both are $0 \mathrm{nT}$ ). To show the thermospheric responses to IMF oscillation, the background winds giving in CMIT base run are removed.

\section{Results}

\section{Broken Mean Circulation}

Figure $1 \mathrm{a}$ is the UT variation of IMF Bz on Nov 11, 2003, which oscillated between northward and southward directions with periods from tens of minutes to several hours. The IMF data comes from the ACE spacecraft in L1 (Lagrange point) orbits (OMNI website). The observed Bz variations on Nov 11, 2003 have temporal oscillations, with similar period and magnitude as modeled ones. Figure $1 \mathrm{~b}$ shows the neutral densities at $~ 12$ LT observed by CHAMP on Nov 11, 2003 at middle and low latitudes. Note here that the neutral density during quiet times (Nov. $8,2003, \mathrm{Kp} \approx 1.8$ ) is removed as the background. The $\mathrm{X}$-axis in Figure $1 \mathrm{~b}$ also denotes the latitudes of CHAMP orbits. The disturbances in neutral density are the error of CHAMP observations, and are smooth. Due to the lack of meridional winds observations by CHAMP, the neutral densities are used to represent TADs. In Figure 1b, the disturbed neutral density shows two different features. One is the disturbed density occurring at almost the same time at $-60^{\circ} \sim-30^{\circ}$ geographic latitudes (GLat) at 05 UT on Nov. 11, 2003 (see orbit 2). The density changes at $-60^{\circ} \sim-30^{\circ}$ geographic latitudes (GLat) are much stronger at orbit 2 than that at other orbits. Note that the CHAMP satellite has a speed of $7.6 \mathrm{~km} / \mathrm{s}$, which is much faster than the propagation of TADs. Thus, the density changes at orbit 2 can be regarded as a response without significant time delay at latitudes. The other is the propagation of the density disturbance from $-30^{\circ} \mathrm{GLat}$ to $-10^{\circ} \mathrm{GLat}$ in $\sim 2$ hours, with a phase speed of $\sim 300 \mathrm{~m} / \mathrm{s}$ (magenta arrows in Figure $1 \mathrm{~b}$ ). The density changes at orbit 3 and $-30^{\circ} \sim-10^{\circ} \mathrm{GLat}$ are enhanced, which could be propagated from high latitudes as observed at orbit 2 . These two features demonstrate the broken mean circulation as shown in Figures $1 \mathrm{~b}$ and $1 \mathrm{c}$. Figure $1 \mathrm{c}$ is the universal time changes of neutral mass density observed by CHAMP, as reported in Figure 3 of Liu and Lühr (2005). The broken mean circulation structure is indicated by the black arrows. The TADs in neutral density propagates equatorward from $\sim 60^{\circ} \mathrm{GLat}$ at $17 \mathrm{UT}$ to $20^{\circ} \mathrm{GL}$ at at $20 \mathrm{UT}$. In addition, the neutral density at $-60^{\circ} \sim 20^{\circ}$ GLat seems to be enhanced at almost the same time. Moreover, during the storm period (29-31 Oct, 2003), the electron density also exhibited an evident combined feature of traveling ionospheric disturbances (TIDs) and the simultaneous responses (Figure 1d). The electron density at $40^{\circ} \sim 70^{\circ}\left(-40^{\circ}\right.$ $\sim-60^{\circ}$ ) GLat in the Northern (Southern) Hemisphere increases at almost the same time, as indicated by the vertical black arrows. Then, the enhancement travelled to low latitudes in $\sim 4$ hours (the sloped black arrows).

The broken mean circulation is the combined characters of the traveling atmospheric disturbances and simultaneous changes in meridional winds. The broken mean circulation is shown in the observed neutral 
density. To disclose this phenomenon, two idealized numerical experiments are performed by using the CMIT model. The reason why idealized cases are used in the following study instead of the realistic case, is that the external driving (e.g., geomagnetic activity) are significantly variant in the realistic case. In the idealized case, we can hold the external condition unchanged and only change IMF condition. Figure 2 shows the geographic latitude and longitude variations of the modeled meridional winds (Figures $2 \mathrm{a}$ and 2b) and their disturbances (Figure 2c) at 12 LT. Here positive value stands for northward direction. At a fixed local time, one longitude corresponds to one universal time. Thus, the plot gives the temporal and longitudinal variations of wind changes in global scale. In Figure 2a, there do not exist significant temporal oscillations in the background meridional winds. In Figure $2 b$, the meridional winds show outstanding periodic variations as that of IMF Bz. The equatorward penetration of TADs in meridional winds seems to be much stronger at above $20^{\circ}$ MLat than that at the equator of $0^{\circ} \sim 20^{\circ}$ MLat (the area closed by black and red lines). Thus, to clearly shown the wind disturbances, a differential analysis between modeled meridional winds in Figures $2 \mathrm{a}$ and $2 \mathrm{~b}$ has been carried out, which has been shown in Figure 2c. At $\sim 100^{\circ}$ GLon, the notable TADs in a phase speed of $\sim 462 \mathrm{~m} / \mathrm{s}$ are generated in both hemispheres and propagate from high to low latitudes, which are shown by red and black arrows. In the Southern Hemisphere, the TADs occurring at $-30^{\circ} \sim 120^{\circ}$ GLon propagate to lower latitudes, with several sudden changes in the wave phase along the propagation direction. This change in wave phase tends to occur at higher latitudes with UT, for instance, from $\left(-40^{\circ} \mathrm{GLat}, 90^{\circ} \mathrm{GLon}\right)$ to $\left(-50^{\circ} \mathrm{GLat}, 30^{\circ} \mathrm{GLon}\right)$. At $120^{\circ} \sim 180^{\circ} \mathrm{GLon}$, the magnitude of TADs which is the deviation from the background value is weaker ( 8 $\mathrm{m} / \mathrm{s}$ ) than that at other longitudes, but shows similar broken structures as that at $-30^{\circ} \sim 120^{\circ} \mathrm{GLon}$. The broken mean circulation, a combined effect of TADs and the simultaneous response of neutral winds, is found in previous observations (Figure 3 of Liu and Lühr., 2005). Liu and Lühr (2005) only showed the neutral density variations derived from CHAMP observations during the storm period in November, 2003, but did not mention the broken men circulation. The broken mean circulation does not catch so much attention in the literature, which is a major new finding in our work. Furthermore, as our previous work disclosed (Zhang et al., 2019), the CMIT model can be used in this work to investigate the ideal cases of IMF Bz oscillations and to understand the physical mechanisms. In our study, the broken mean circulation is well reproduced in our simulations, but not at the same latitudes and events. We understand that the approach is qualitative rather than quantitative. However, this does not conflict to achieve the major conclusion and has little influence on the reliability of our conclusions.

\section{Standing Features in Meridional Winds}

In the Northern Hemisphere (Figure 2c), the TADs in meridional winds can be found at longitudes of $-60^{\circ} \sim 120^{\circ} \mathrm{GLon}$ due to pressure gradient. The magnitude of TADs at $-60^{\circ} \sim 0^{\circ} \mathrm{GLon}$ is stronger $(\sim 30 \mathrm{~m} / \mathrm{s})$ than that at $0^{\circ} \sim 120^{\circ} \mathrm{GLon}(\sim 20 \mathrm{~m} / \mathrm{s})$. However, those notable equatorward TADs stand around $20^{\circ} \mathrm{MLat}$ (black line). At $-180^{\circ} \sim-60^{\circ}$ GLon and $120^{\circ} \sim 180^{\circ}$ GLon, the periodic wind disturbance originating from high latitudes does not have any notable time delay with respect to latitudes, which are caused by the ion 
drag. Similar to TADs at $-60^{\circ} \sim 120^{\circ} \mathrm{GLon}$, these instances wind responses also stand at around $20^{\circ}$ MLat. We will use the model to further investigate the physical mechanism of these standing features.

One can notice that the meridional wind changes that show significant hemispheric asymmetry and longitudinal differences, including TADs and simultaneous responses without significant time delay with respect to latitudes, are unexpected and seldom investigated during the temporal oscillations of IMF Bz. The broken mean circulation occurs in the Southern Hemisphere, while uninterrupted TADs and standing features appear in the Northern Hemisphere. The longitudinal differences and hemispheric asymmetry will be further explored in the discussion section.

\section{Discussion}

As disclosed by previous work, the thermospheric winds are determined by a balance between several forcing (Wang and Lühr, 2016). For instance, the pressure gradient, ion drag, viscosity, Coriolis, and momentum advection. Similar to Hsu et al. (2016), we perform a term analysis of these forcing in meridional momentum equation. In this work, only the ion drag and pressure gradient are shown, because they are dominant over the other drivers.

\section{Broken Mean Circulation}

Figure 3 shows the differences in forcing terms of meridional winds between the CMIT 60-min oscillation case and the background run. Figure 3 a shows the differential total accelerations in the meridional wind, where broken mean circulation appears at $-30^{\circ} \sim 180^{\circ}$ GLon in the Southern Hemisphere. A comparison between Figures 3a and $3 \mathrm{~b}$ (acceleration due to pressure gradient), 3c (acceleration due to ion drag) shows that the broken mean circulation result from the combined roles of ion drag and pressure gradient. These are associated with both penetration electric fields and the energy input from the solar wind to the upper thermosphere (Dungey, 1961). Wherever the ion drag overwhelms the pressure gradient, the propagation of TADs will be broken into several pieces. Under the northward IMF condition, when the ion drag is weaker than the pressure gradient, the uninterrupted TADs become obvious.

The pressure gradient is the reason for the propagation of wind disturbances from high to low latitudes, which is related to the enhanced Joule heating and related neutral temperature. Under the southward IMF Bz condition, the energy carried in the solar wind can be fully and directly deposited into the upper atmosphere due to the dayside magnetic reconnection (Liu et al., 2018a). Due to the nightside reconnection, the energy is also released into the upper thermosphere from the magneto-tail (Liu et al., 2018a). The energy carried by solar wind accumulates in the magneto-tail, and then under the effects of the solar wind variability or magnetosphere internal processes, it is suddenly released. Both processes contribute to the enhanced Joule heating and neutral temperature in the polar region (as shown in Figure 4d). 
The ion drag is vital for the development of the broken mean circulation, which is related to both ion density and velocity. The former is related to the vertical transport caused by both ExB drift and neutral winds, and the latter is related to ExB ion drift (Richmond, 1995). During the rapid temporal change of IMF, the prompt penetration electric fields (PPEF) from the high to the low latitudes occurs (Nishida, 1968). It is well-known that PPEF is induced by an imbalance between Region 1 (R1) and Region 2 (R2) field-aligned currents (FACs) at high latitudes. The under-shielding can appear when R1 FACs have a stronger amplitude than R2 FACs under southward IMF Bz, and overshielding can occur when R1 FACs have a weaker amplitude than R2 FACs. As disclosed in previous works, PPEF produces the changes of ionospheric plasma density and vertical ion drift at different latitudes at the same time, because it occurs instantaneously in global scale (e.g., Liu et al., 2004; Rodríguez-Zuluaga et al., 2016; Yizengaw et al., 2004).

Figure 4 shows the geographic longitude and latitude variations of the disturbed electron density, vertical plasma velocity, meridional plasma velocity, and neutral temperature. The enhancements of wind and temperature at $-60^{\circ} \sim-180^{\circ}$ GLon might be related to the longitudinal patterns of electron density, which have a peak in America sector and causing by the topology of the geomagnetic field (Wang and Zhang, 2017; Zhang et al., 2019). The wind and temperature can be affected by electron density via ion-neutral collision. The $\mathrm{E} \times \mathrm{B}$ changes in America sector might be due to the offset between geographic latitudes and geomagnetic latitudes which are more notable at $-60^{\circ} \sim 180^{\circ} \mathrm{GLon}$. One can notice that both the disturbed plasma density and vertical plasma velocity (Figures $4 \mathrm{a}$ and $4 \mathrm{~b}$ ) are stronger at $0^{\circ} \sim-180^{\circ}$ GLon than that at $0^{\circ} \sim 180^{\circ} \mathrm{GLon}$, due to the configurations of the geomagnetic field. The geomagnetic field can influence the disturbance of plasma, because the plasma can be transport along the geomagnetic field lines by thermospheric winds (Rishbeth, 1967). The ion drag in the Southern Hemisphere comes mainly from the ExB ion drifts because the plasma density changes are very weak. It can be seen from Figure $4 \mathrm{c}$ that the meridional plasma velocity in the Southern Hemisphere is much stronger at $-60^{\circ} \sim 180^{\circ} \mathrm{GLon}(\sim 60 \mathrm{~m} / \mathrm{s})$ than that at the remaining longitudes $(\sim 15 \mathrm{~m} / \mathrm{s})$ corresponding to the geomagnetic field geometry. As disclosed in Zhang S. et al., (2012) and Zhang K. et al., (2018), the field-aligned plasma velocity due to thermospheric winds is related to geomagnetic inclination and declination. The equation of wind projection along the magnetic field lines is:

$$
\mathrm{VV}=v_{n} \cos D \cos |I| \sin |I| \pm u_{n} \sin D \cos |I| \sin |I|
$$

where $V V$ is the plasma velocity in the vertical direction driven by the winds, $V n$ is the meridional winds, Un is the zonal winds, / is the inclination, $D$ is the declination, the positive (negative) signal stands for that in the Southern (Northern) Hemisphere. Field-aligned winds push the plasma to move along the magnetic field lines. In addition, the plasma can also be driven upward or downward due to eastward or westward electric fields ( $E \times B$ drifts), which also depends on the geomagnetic field configuration. The offset between geographic latitude and geomagnetic latitude is different at different longitudes. Thus, plasma density has a notable longitudinal dependence. The longitudinal distribution of electron density can feed 
back to further influence the neutral winds via ion drag, as the two processes that determine the ion drag, the electron density, and the relative velocity between the ions and neutrals all have longitudinal dependence. This further demonstrates that the IT system is a closely coupled, nonlinear one. This is because the offset between geographic latitudes and geomagnetic latitudes is more notable at $-60^{\circ} \sim$ $180^{\circ}$ GLon. This is consistent with the longitudinal variation of ion drag as shown in Figure 3c. The longitudinal variation of the ion drag related to the ExB drift can explain the longitudinal variation of the broken mean circulation.

There also exists a significant hemispheric asymmetry in the broken mean circulation, caused by the combined roles of pressure gradient and ion drag. In the longitude sector, both the effects of pressure gradient and ion drag are strong enough and cannot overwhelm each other in the Southern Hemisphere. As shown in Figure 4a, the electron density enhancements are more than $3 \times 10^{11} \mathrm{~m}^{-3}$ at geomagnetic latitudes above $20^{\circ} \mathrm{MLat}$ in the Northern Hemisphere, which are significantly stronger than those in the Southern Hemisphere $\left(1 \times 10^{11} \mathrm{~m}^{-3}\right)$. Thus, the ion drag effects, which are proportional to the plasma density, show the corresponding patterns. In addition, the plasma density changes in the Northern Hemisphere are much larger at $0^{\circ} \sim-180^{\circ}$ GLon $\left(\sim 5 \times 10^{11} \mathrm{~m}^{-3}\right)$ than those at $0^{\circ} \sim 180^{\circ} \mathrm{GLon}\left(\sim 3 \times 10^{11}\right.$ $\left.\mathrm{m}^{-3}\right)$, thus the ion drag effects are also stronger in the $0^{\circ} \sim-180^{\circ}$ GLon sector. Note here that in Figure $3 \mathrm{~b}$, the pressure gradient that is associated with temperature disturbances under the temporal oscillations of IMF Bz conditions has similar magnitudes in the two hemispheres, and does not show outstanding longitudinal patterns as that in the ion drag effects. Then, the role of ion drag overpowers the pressure gradient at this sector and is overwhelmed at the remaining longitudes.

\section{Standing signature}

As shown in Figure 2c, the TADs of meridional winds stand at $20^{\circ}$ MLat. A similar standing feature can be found in the plasma density (Figure 4a) and neutral temperature (Figure 4d). As shown in Figure 3, the standing feature in the meridional wind is due to the combined roles of ion drag and pressure gradient.

As disclosed in the literature (e.g., Breig, 1987; Fejer et al., 1999), the ExB drifts, ambipolar diffusion, thermospheric neutral winds, and chemistry are vital in the variations of ionospheric electron density at middle and low latitudes. Daytime PPEF is eastward for the undershielding and westward for the overshielding (Peymirat et al., 2000). Then, the ionospheric plasma is driven upward/downward along the magnetic field line, causing the density enhancement/decrease that is dependent on the longitudes in the LT-fixed map, as shown in Figure $4 \mathrm{a}$. The plasma density enhances at almost all longitudes at $\sim 20^{\circ} \mathrm{MLat}$ (black curve line, Figure 4a) in the Northern Hemisphere. This could be related to the standing feature of TADs (Figure 2c). The density enhances significantly at MLat above $20^{\circ}$ MLat, introducing strong ion drag effects to the equatorward propagation TADs in meridional winds. Thus, the meridional winds are slowed down in this sector, with a pattern of standing feature. The plasma moves to high altitudes at the equator, then decrease to low altitudes along the magnetic field line for the ambipolar diffusion, summerwinter thermospheric winds, and gravity force, producing the notable equatorial ion anomaly (EIA) structures that are significant at $\sim 20^{\circ}$ MLat (black curve line, Figure $4 a$ ). At $\sim 20^{\circ}$ MLat, the density 
changes are stronger at $-60^{\circ} \sim-180^{\circ} \mathrm{GLon}$ and $120^{\circ} \sim 180^{\circ} \mathrm{GLon}$ than those at remaining longitudes due to the geomagnetic field topology, consistent with the results of Immel and Mannucci (2013) and Greer and Ridley (2017). Because ionospheric plasma can move along the geomagnetic field lines by ambipolar diffusion and neutral winds. The plasma can also be transported upward/downward under the effects of eastward/westward electric fields (ExB drifts). The equatorward/poleward winds can move the plasma along the magnetic field lines (upward/downward) due to the wind projection as shown in equation (1), producing density changes. The transportation of plasma due to the winds has a close relationship with the geomagnetic configuration. For instance, when the declination is negative (positive), the eastward winds can move the plasma to a lower (higher) altitude, causing a decrease (enhancement) of electron density. In the Northern (Southern) Hemisphere, there are two (one) zones of negative declination and two (one) zones of positive declination. Thus, the electron densities with the modification of geomagnetic field morphology can have large longitudinal variations. Thus, the effects of ion drag overpower the pressure gradient and prevent the propagating of TADs at $-60^{\circ} \sim-180^{\circ}$ GLon and $120^{\circ} \sim$ $180^{\circ} \mathrm{GLon}$, which is a key factor in the standing feature in meridional winds at these longitudes.

At $-60^{\circ} \sim 120^{\circ} \mathrm{GLon}$, the effect of the pressure gradient on the meridional wind dominates over the ion drag when the electron density is weak (Figure 3a). Note here that the temperature seems to enhance more at latitudes above $20^{\circ} \mathrm{MLat}$ than that at $0^{\circ} \sim 20^{\circ} \mathrm{MLat}$, indicated by the black curve line (Figure $4 d)$. Thus, the standing feature at this longitudinal sector seems to be related to the neutral temperature changes, which exhibit a similar structure. At this longitude sector, the offset between the geomagnetic and geographic latitudes is more notable, correspondingly the neutral temperature change can be larger. Because the electron density changes are noticeable in this longitude sector, and thus the corresponding neutral temperature change due to the plasma collisional heating, which is the dominant heating mechanism for the neutrals in the upper thermosphere, is large (Zhang et al., 2018).

In addition, the standing feature appears only in the Northern Hemisphere, showing a significant hemispheric asymmetry. This asymmetry is closely related to the electron density changes under the temporal oscillations of IMF Bz conditions. At $\sim 300 \mathrm{~km}$, the electron density (Figure 4a) changes are much larger in the Northern Hemisphere than those in the opposite hemisphere. The density changes in the Northern Hemisphere are greater than $3 \times 1011 \mathrm{~m}-3$ at geomagnetic latitudes along and above $20^{\circ}$ MLat, whereas those are $\sim 1 \times 1011$ m-3 at the conjugated latitudes in the Southern Hemisphere. The stronger the plasma density changes are, the larger influences of ion drag on the meridional winds are (Figures $3 \mathrm{a}$ and $3 \mathrm{c}$ ). Thus, the equatorward propagation of TADs in the Northern Hemisphere stands at $\sim 20^{\circ} \mathrm{MLat}$, and does not appear in the Southern Hemisphere.

\section{Conclusion}

Using coupled magnetosphere-thermosphere-ionosphere model results, the hemispheric and longitudinal differences of the meridional wind changes during oscillating interplanetary magnetic field Bz at 60-min are explored in this work. The main results are shown below. 
1) The broken mean circulation only exists at $0^{\circ} \sim 180^{\circ}$ geographic longitude (GLon) in the Southern Hemisphere, which is due to the combined roles of the pressure gradient and ion drag forces.

2) The standing features in TADs of meridional winds are found at $\sim 20^{\circ}$ magnetic latitude (MLat), which are induced by the geomagnetic field configurations, neutral temperature, and electron density changes.

\section{List Of Abbreviations}

Interplanetary magnetic field (IMF).

Magnetic latitude (MLat).

Travelling atmospheric disturbances (TADs).

lonosphere-Thermosphere (IT).

Traveling ionospheric disturbances (TID).

CHAllenging Minisatellite Payload (CHAMP).

Coupled Magnetosphere lonosphere Thermosphere (CMIT).

Thermosphere lonosphere Electrodynamic General Circulation Model (TIEGCM).

Lyon-Fedder-Mobarry (LFM).

Geographic latitudes (GLat).

Geographic longitude (GLon).

Region 1 (R1).

Region 2 (R2).

Field-aligned currents (FACs).

Equatorial ion anomaly (EIA).

\section{Declarations}

\section{Availability of data and materials}

The IMF data comes from OMNI website (https://omniweb.gsfc.

nasa.gov/). The CHAMP thermospheric data is from the website (ftp://isdcftp.gfz-potsdam.de/champ/). The CHAMP neutral density can be downloaded from the website (http://thermosphere.tudelft.nl/). The 
model outputs are stored in the NCAR High Performance Storage System

(https://www2.cisl.ucar.edu/resources/storage-and-file-systems/hpss).

\section{Competing interest}

The authors declare that they have no competing interests.

\section{Funding}

The National Center for Atmospheric Research is sponsored by the National Science Foundation. We are really grateful for the sponsor from the National Nature Science Foundation of China (NO. 41974182, 41674153, 41431073, 41521062 and 42004135), and the Spark Project at Wuhan University (2042020gf0024).

\section{Authors' contributions}

Kedeng Zhang, Hui Wang, Wenbin Wang, Jing Liu made contributes to the theoretic interpretation of results and drafted the manuscript. Kedeng Zhang and Jie Gao made contributions on the data processing and model work.

\section{Acknowledgments}

The operational support of the CHAMP mission by the German Aerospace Center (DLR) are gratefully acknowledged.

\section{References}

Blanc, M., \& Richmond, A. D. (1980). The ionospheric disturbance dynamo. Journal of Geophysical Research: Space Physics, 85(A4), 1669-1686.

Breig, E. L. (1987). Thermospheric ion and neutral composition and chemistry. Reviews of Geophysics, 25(3), 455-470.

Bruinsma, S. L., \& Forbes, J. M. (2007). Global observation of traveling atmospheric disturbances (TADs) in the thermosphere. Geophysical Research Letters, 34(14).

Bruinsma, S. L., \& Forbes, J. M. (2009). Properties of traveling atmospheric disturbances (TADs) inferred from CHAMP accelerometer observations. Advances in Space Research, 43(3), 369-376.

Cnossen, I., and A.D. Richmond (2012). How changes in the tilt angle of the geomagnetic dipole affect the coupled magnetosphere-ionosphere-thermosphere system, J. Geophys. Res., 117, A10317, doi:

10.1029/2012JA018056.

Dungey, J. W. (1961). Interplanetary magnetic field and the auroral zones. Physical Review Letters, 6(2), 47. 
Fejer, B. G., Scherliess, L., \& De Paula, E. R. (1999). Effects of the vertical plasma drift velocity on the generation and evolution of equatorial spread F. Journal of Geophysical Research: Space Physics, 104(A9), 19859-19869.

Fejer, B. G., Jensen, J. W., \& Su, S. Y. (2008). Seasonal and longitudinal dependence of equatorial disturbance vertical plasma drifts. Geophysical Research Letters, 35(20).

Forbes, J. M., G. Lu, S. Bruinsma, S. Nerem, and X. Zhang (2005), Thermosphere density variations due to the 15-24 April 2002 solar events from CHAMP/STAR accelerometer measurements, J. Geophys. Res., 110, A12S27, doi:10.1029/2004JA010856.

Greer, K. R., Immel, T., \& Ridley, A. (2017). On the variation in the ionospheric response to geomagnetic storms with time of onset. Journal of Geophysical Research: Space Physics, 122(4), 4512-4525.

Hagan, M. E., and Forbes, J. M. (2002). Migrating and nonmigrating diurnal tides in the middle and upper atmosphere excited by tropospheric latent heat release. Journal of Geophysical Research: Atmospheres, 107(D24).

Hagan, M. E., \& Forbes, J. M. (2003). Migrating and nonmigrating semidiurnal tides in the upper atmosphere excited by tropospheric latent heat release. Journal of Geophysical Research: Space Physics, 108(A2).

Häusler, K., Lühr, H., Rentz, S., and Köhler, W. (2007). A statistical analysis of longitudinal dependences of upper thermospheric zonal winds at dip equator latitudes derived from CHAMP. Journal of atmospheric and solar-terrestrial physics, 69(12), 1419-1430.

Häusler, K., and Lühr, H. (2009). Nonmigrating tidal signals in the upper thermospheric zonal wind at equatorial latitudes as observed by CHAMP. Ann. Geophys, 27(7), 2643-2652.

Häusler, K., Lühr, H., Hagan, M. E., Maute, A., and Roble, R. G. (2010). Comparison of CHAMP and TIMEGCM nonmigrating tidal signals in the thermospheric zonal wind. Journal of Geophysical Research: Atmospheres, 115(D1).

Heelis, R. A., Lowell, J. K., and Spiro, R. W. (1982). A model of the high-latitude ionospheric convection pattern. Journal of Geophysical Research: Space Physics, 87(A8), 6339-6345.

Hsu, V. W.,J.P.Thayer, W. Wang,and A. Burns (2016), New insights into the complex interplay between drag forces and its thermospheric consequences, J. Geophys. Res. Space Physics, 121, 10,417-10,430, doi:10.1002/2016JA023058.

Immel, T. J., and A. J. Mannucci (2013), lonospheric redistribution during geomagnetic storms, J. Geophys. Res. Space Physics, 118, 7928-7939, doi:10.1002/2013JA018919. 
Lei, J., Wang, W., Burns, A. G., Solomon, S. C., Richmond, A. D., Wiltberger, M., ... \& Reinisch, B. W. (2008). Observations and simulations of the ionospheric and thermospheric response to the December 2006 geomagnetic storm: Initial phase. Journal of Geophysical Research: Space Physics, 113(A1).

Li, G., Ning, B., Hu, L., Liu, L., Yue, X., Wan, W., ... \& Xu, J. S. (2010). Longitudinal development of lowlatitude ionospheric irregularities during the geomagnetic storms of July 2004. Journal of Geophysical Research: Space Physics, 115(A4).

Liu, H., and H. Lühr (2005), Strong disturbance of the upper thermospheric density due to magnetic storms: CHAMP observations, J. Geophys. Res., 110, A09S29, doi:10.1029/2004JA010908.

Liu, J., Zhao, B., \& Liu, L. (2010, March). Time delay and duration of ionospheric total electron content responses to geomagnetic disturbances. Annales Geophysicae (09927689) 28, no. 3 (2010).

Liu, J., Liu, L., Nakamura, T., Zhao, B., Ning, B., \& Yoshikawa, A. (2014). A case study of ionospheric storm effects during long-lasting southward IMF Bz-driven geomagnetic storm. Journal of Geophysical Research: Space Physics, 119(9), 7716-7731.

Liu, J., Wang, W., Zhang, B., Huang, C., \& Lin, D. (2018a). Temporal Variation of Solar Wind in Controlling Solar Wind-Magnetosphere-lonosphere Energy Budget. Journal of Geophysical Research: Space Physics, 123(7), 5862-5869.

Liu, J., Wang, W., Burns, A., Oppenheim, M., \& Dimant, Y. (2018b). Faster traveling atmosphere disturbances caused by polar ionosphere turbulence heating. Journal of Geophysical Research: Space Physics, 123(3), 2181-2191.

Lyon, J. G., Fedder, J. A., \& Mobarry, C. M. (2004). The Lyon-Fedder-Mobarry (LFM) global MHD magnetospheric simulation code. Journal of Atmospheric and Solar-Terrestrial Physics, 66(15), 13331350.

Maute, A., Richmond, A. D., \& Roble, R. G. (2012). Sources of low-latitude ionospheric E × B drifts and their variability. Journal of Geophysical Research, 117, A06312. https://doi.org/10.1029/2011JA017502

Merkin, V. G., Milikh, G., Papadopoulos, K., Lyon, J., Dimant, Y. S., Sharma, A. S., ... \& Wiltberger, M. (2005). Effect of anomalous electron heating on the transpolar potential in the LFM global MHD model. Geophysical research letters, 32(22).

Nishida, A. (1968). Coherence of geomagnetic DP 2 fluctuations with interplanetary magnetic variations. Journal of Geophysical Research, 73(17), 5549-5559.

Oberheide, J., Forbes, J. M., Häusler, K., Wu, Q., and Bruinsma, S. L. (2009). Tropospheric tides from 80 to $400 \mathrm{~km}$ : Propagation, interannual variability, and solar cycle effects. Journal of Geophysical Research: Atmospheres, 114(D1). 
Oliveira, D. M., Zesta, E., Schuck, P. W., \& Sutton, E. K. (2017). Thermosphere global time response to geomagnetic storms caused by coronal mass ejections. Journal of Geophysical Research: Space Physics, 122, 10,762-10,782. https://doi.org/10.1002/2017JA024006.

Otsuka, Y., Shiokawa, K., Ogawa, T., \& Wilkinson, P. (2004). Geomagnetic conjugate observations of medium-scale traveling ionospheric disturbances at midlatitude using all-sky airglow imagers. Geophysical research letters, 31(15).

Peymirat, C., Richmond, A. D., \& Kobea, A. T. (2000). Electrodynamic coupling of high and low latitudes: Simulations of shielding/overshielding effects. Journal of Geophysical Research: Space Physics, 105(A10), 22991-23003.

Reigber, C., Lühr, H., and Schwintzer, P. (2002). CHAMP mission status. Advances in Space Research, 30(2), 129-134.

Richards, P. G., Fennelly, J. A., and Torr, D. G. (1994). EUVAC: A solar EUV flux model for aeronomic calculations. Journal of Geophysical Research: Space Physics, 99(A5), 8981-8992.

Richmond, A. D., Ridley, E. C., and Roble, R. G. (1992). A thermosphere/ionosphere general circulation model with coupled electrodynamics. Geophysical Research Letters, 19(6), 601-604.

Richmond, A. D. (1995), lonospheric electrodynamics, in Handbook of lonospheric Electrodynamics, vol. II, pp. 249-290, CRC Press, Boca Raton, Fla

Ridley, A. J. (2005). A new formulation for the ionospheric cross polar cap potential including saturation effects. In Annales Geophysicae (Vol. 23, No. 11, pp. 3533-3547).

Rishbeth, H. (1967). The effect of winds on the ionospheric F2-peak. Journal of Atmospheric and Terrestrial Physics, 29(3), 225-238. https://doi.org/10.1016/0021-9169(67)90192-4.

Rodríguez-Zuluaga, J., Radicella, S. M., Nava, B., Amory-Mazaudier, C., Mora-Páez, H., \& Alazo-Cuartas, K. (2016). Distinct responses of the low-latitude ionosphere to CME and HSSWS: The role of the IMF Bz oscillation frequency. Journal of Geophysical Research: Space Physics, 121(11).

Sahai, Y., Fagundes, P. R., Becker-Guedes, F., Abalde, J. R., Crowley, G., Pi, X., ... \& Bittencourt, J. A. (2004, September). Longitudinal differences observed in the ionospheric F-region during the major geomagnetic storm of 31 March 2001. In Annales Geophysicae (Vol. 22, No. 9, pp. 3221-3229).

Sharma, S., Galav, P., Dashora, N., \& Pandey, R. (2011, June). Longitudinal study of the ionospheric response to the geomagnetic storm of 15 May 2005 and manifestation of TADs. In Annales Geophysicae (Vol. 29, No. 6, pp. 1063-1070). Copernicus GmbH.

Shiokawa, K., Ihara, C., Otsuka, Y., \& Ogawa, T. (2003). Statistical study of nighttime medium-scale traveling ionospheric disturbances using midlatitude airglow images. Journal of Geophysical Research: 
Space Physics, 108(A1).

Sutton, E. K., Nerem, R. S., \& Forbes, J. M. (2007). Density and winds in the thermosphere deduced from accelerometer data. Journal of Spacecraft and Rockets, 44(6), 1210-1219.

Sutton, E. K., Forbes, J. M., \& Knipp, D. J. (2009). Rapid response of the thermosphere to variations in Joule heating. Journal of Geophysical Research: Space Physics, 114(A4).

Thome, G. D. (1964). Incoherent scatter observations of traveling ionospheric disturbances. Journal of Geophysical Research, 69(19), 4047-4049.

Wang, H., and Lühr, H. (2016). Longitudinal variation in zonal winds at subauroral regions: Possible mechanisms. Journal of Geophysical Research: Space Physics, 121(1), 745-763.

Wang, H., and Zhang, K. (2017). Longitudinal structure in electron density at mid-latitudes: upwardpropagating tidal effects. Earth, Planets and Space, 69(1), 11.

Wang, W., Wiltberger, M., Burns, A. G., Solomon, S. C., Killeen, T. L., Maruyama, N., \& Lyon, J. G. (2004). Initial results from the coupled magnetosphere-ionosphere-thermosphere model: thermosphereionosphere responses. Journal of atmospheric and solar-terrestrial physics, 66(15), 1425-1441.

Wang, W., Lei, J., Burns, A. G., Wiltberger, M., Richmond, A. D., Solomon, S. C., ... \& Anderson, D. N. (2008). lonospheric electric field variations during a geomagnetic storm simulated by a coupled magnetosphere ionosphere thermosphere (CMIT) model. Geophysical Research Letters, 35(18).

Wei, Y., M. Hong, W. Wan, A. Du, J. Lei, B. Zhao, W. Wang, Z. Ren, and X. Yue (2008), Unusually long lasting multiple penetration of interplanetary electric field to equatorial ionosphere under oscillating IMF Bz, Geophys. Res. Lett., 35, L02102, doi:10.1029/2007GL032305.

Wiltberger, M., Wang, W., Burns, A. G., Solomon, S. C., Lyon, J. G., \& Goodrich, C. C. (2004). Initial results from the coupled magnetosphere ionosphere thermosphere model: Magnetospheric and ionospheric responses. Journal of atmospheric and solar-terrestrial physics, 66(15), 1411-1423.

Xiong, C., H. Lühr, and B.G. Fejer (2015), Global features of the disturbance winds during storm time deduced from CHAMP observations, J. Geophys. Res. Space Physics, 120, 5137-5150, doi:10.1002/2015JA021302.

Xiong, C., Lühr, H., \& Fejer, B. G. (2016). The response of equatorial electrojet, vertical plasma drift, and thermospheric zonal wind to enhanced solar wind input. Journal of Geophysical Research: Space Physics, 121(6), 5653-5663.

Yizengaw, E., Essex, E. A., \& Birsa, R. (2004, September). The Southern Hemisphere and equatorial region ionization response for a 22 September 1999 severe magnetic storm. Annales Geophysicae, 22 (8), 27652773. 
Zhang, K., Wang, W., Wang, H., Dang, T., Liu, J., \& Wu, Q. (2018). The Longitudinal Variations of Upper Thermospheric Zonal Winds Observed by the CHAMP Satellite at Low and Midlatitudes. Journal of Geophysical Research: Space Physics, 123(11), 9652-9668.

Zhang, K., Liu, J., Wang, W., \& Wang, H. (2019). The effects of IMF Bz periodic oscillations on thermospheric meridional winds. Journal of Geophysical Research: Space Physics.

Zhang, S.-R., J. C. Foster, J. M. Holt, P. J. Erickson, and A. J. Coster (2012), Magnetic declination and zonal wind effects on longitudinal differences of ionospheric electron density at midlatitudes, J. Geophys. Res., 117, A08329, doi:10.1029/2012JA017954.

\section{Figures}


(a) IMF Bz
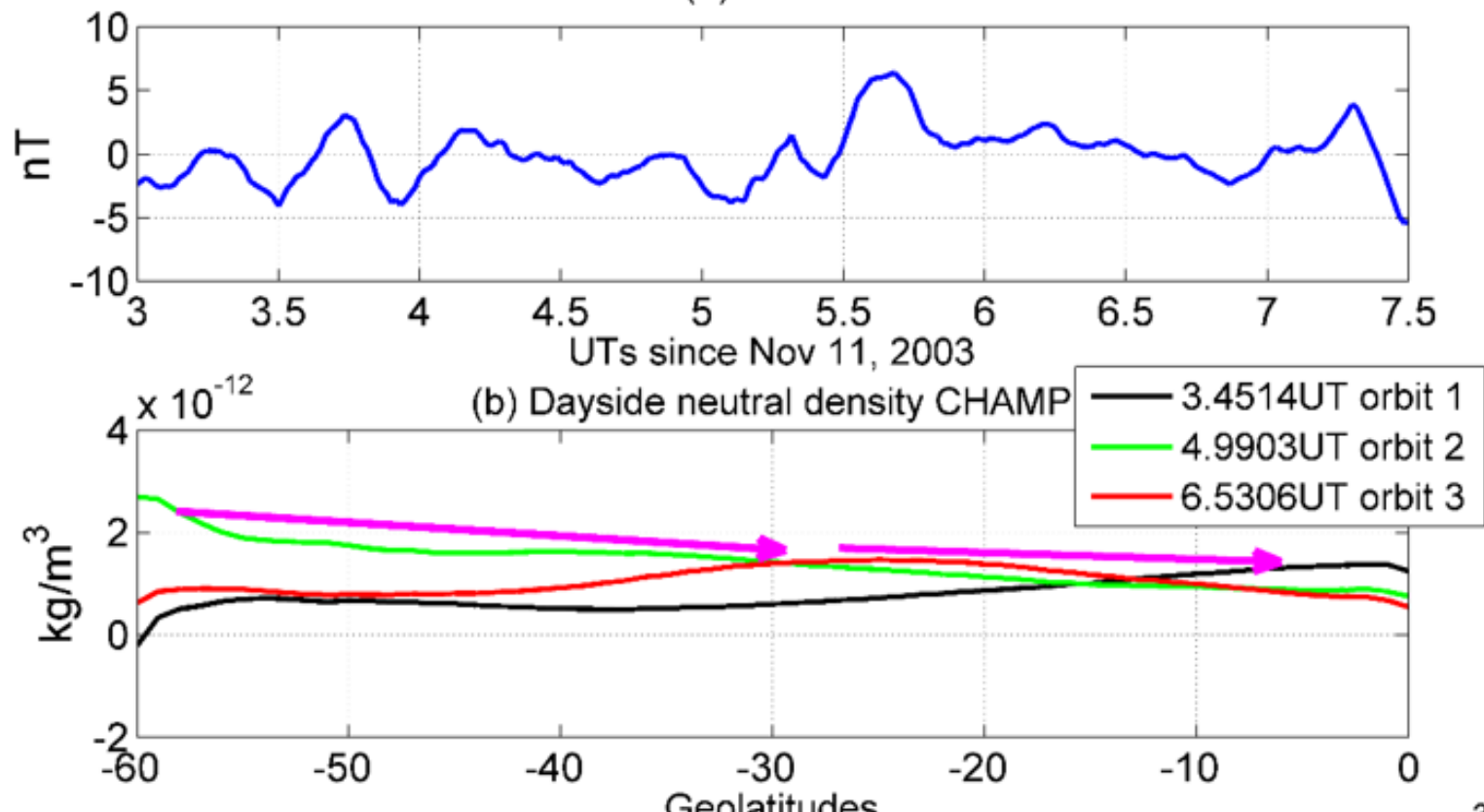

(c) Thermospheric Density CHAMP 29-31 Oct, $2003 \quad \mathrm{~kg} / \mathrm{m}^{3} 10^{-11}$

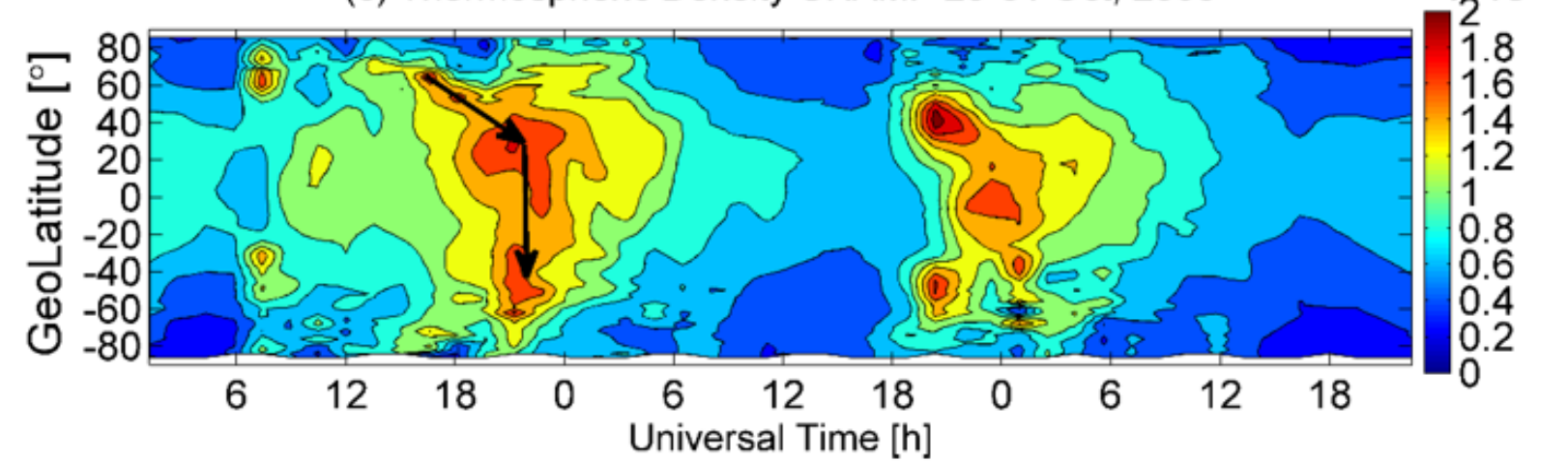

(d) Electron Density CHAMP 29-31 Oct, 2003

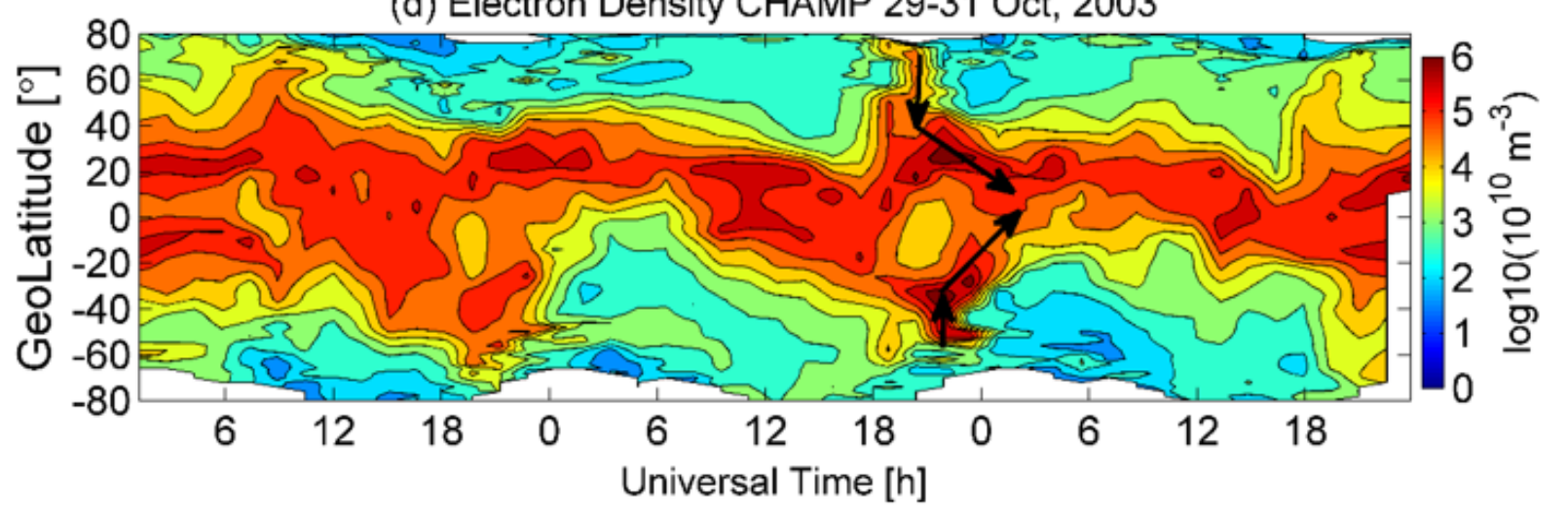

\section{Figure 1}

(a) The universal time (UT) oscillations of IMF Bz on Nov 11, 2003. (b) The geographic latitude variations of neutral density changes observed by CHAMP satellite on Nov 11, 2003. The background neutral density during the quiet time (Nov. 8) has been removed. The average UT for three CHAMP orbits was 03 UT, 05 UT, and 06 UT. The local time of the CHAMP orbit is 12 LT. The magenta arrows show the equatorward propagation of TADs in neutral density. (c) The universal Time changes of neutral density 
observed by CHAMP are the same as that reported in Figure 3 of Liu and Lühr, (2005). The black arrows overplotted are the combined effects of the traveling atmospheric disturbances and simultaneous responses in neutral density on 29-31 Oct, 2003. (d) The same as Figure 1c, but for the electron density observed by CHAMP. The black arrows overplotted are the combined effects of the traveling ionospheric disturbances and simultaneous responses in electron density on 29-31 Oct, 2003.

(a) CMIT VN Background It:12h $\mathrm{m} / \mathrm{s}$
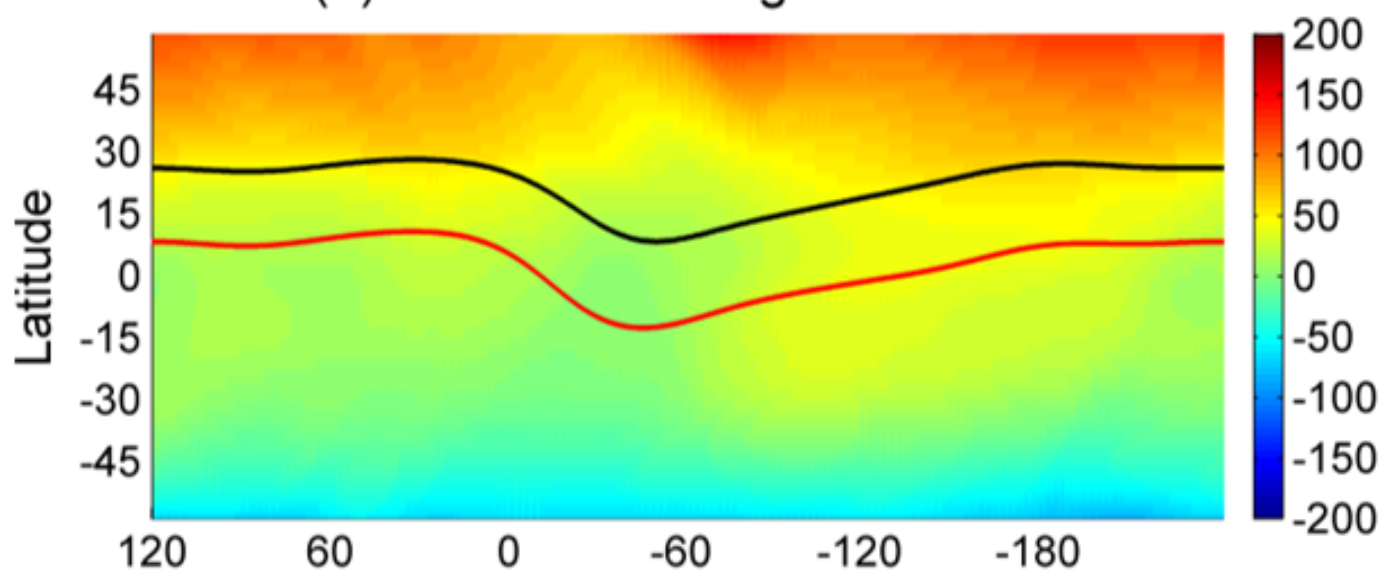

(b) CMIT VN osc60 It:12h

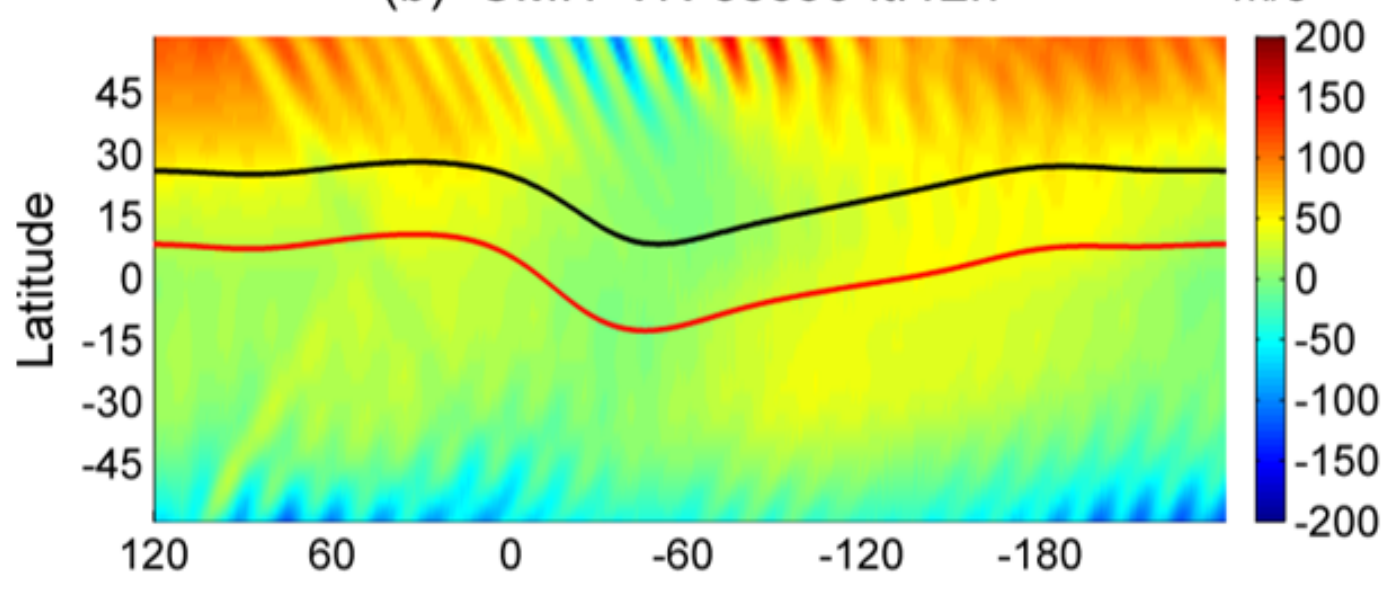

(c) CMIT VN It:12h $\mathrm{m} / \mathrm{s}$

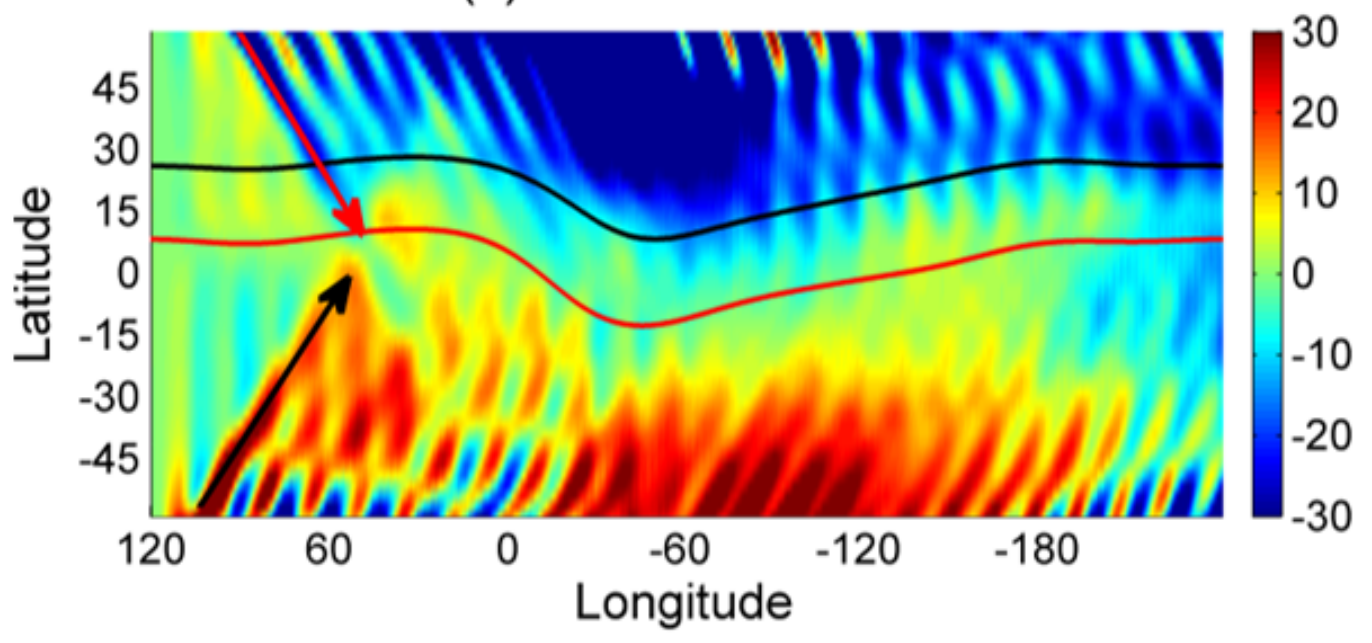

Figure 2 
The geographic longitude and latitude variations of thermospheric meridional (VN) winds in the base case (a), in the 60-min case (b), and the wind responses (c) to the temporal oscillations of IMF Bz in the 60 -min case at $12 \mathrm{LT}$. The background winds in the CMIT base case have been removed from that in the 60-min case to show the wind responses. The red and black lines overplotted are the geomagnetic equator and $20^{\circ} \mathrm{MLAT}$, respectively. The positive in meridional winds is northward. The speed is given in $\mathrm{m} / \mathrm{s}$. The pressure level is $2.875(\sim 315 \mathrm{~km})$. The red and black arrows show the equatorward propagation of TADs in meridional winds.

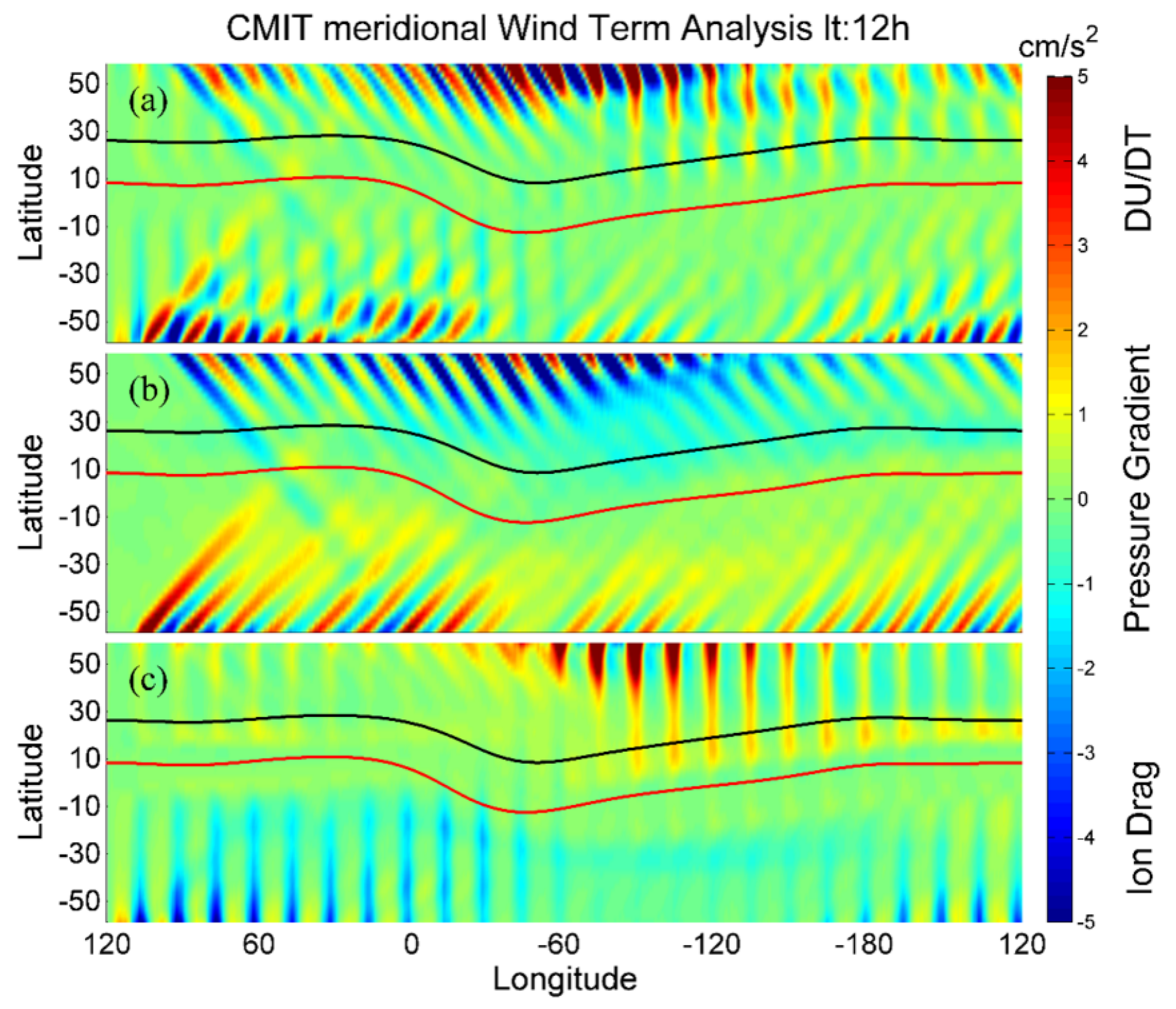

Figure 3

Differences of forcing terms of meridional winds between CMIT 60-min oscillation case and the base run. The top to bottom panels are the acceleration changes due to all forcing, the pressure gradient, and ion drag, respectively. The acceleration is given in $\mathrm{cm} / \mathrm{s} 2$. The pressure level is $2.875(\sim 315 \mathrm{~km})$. 


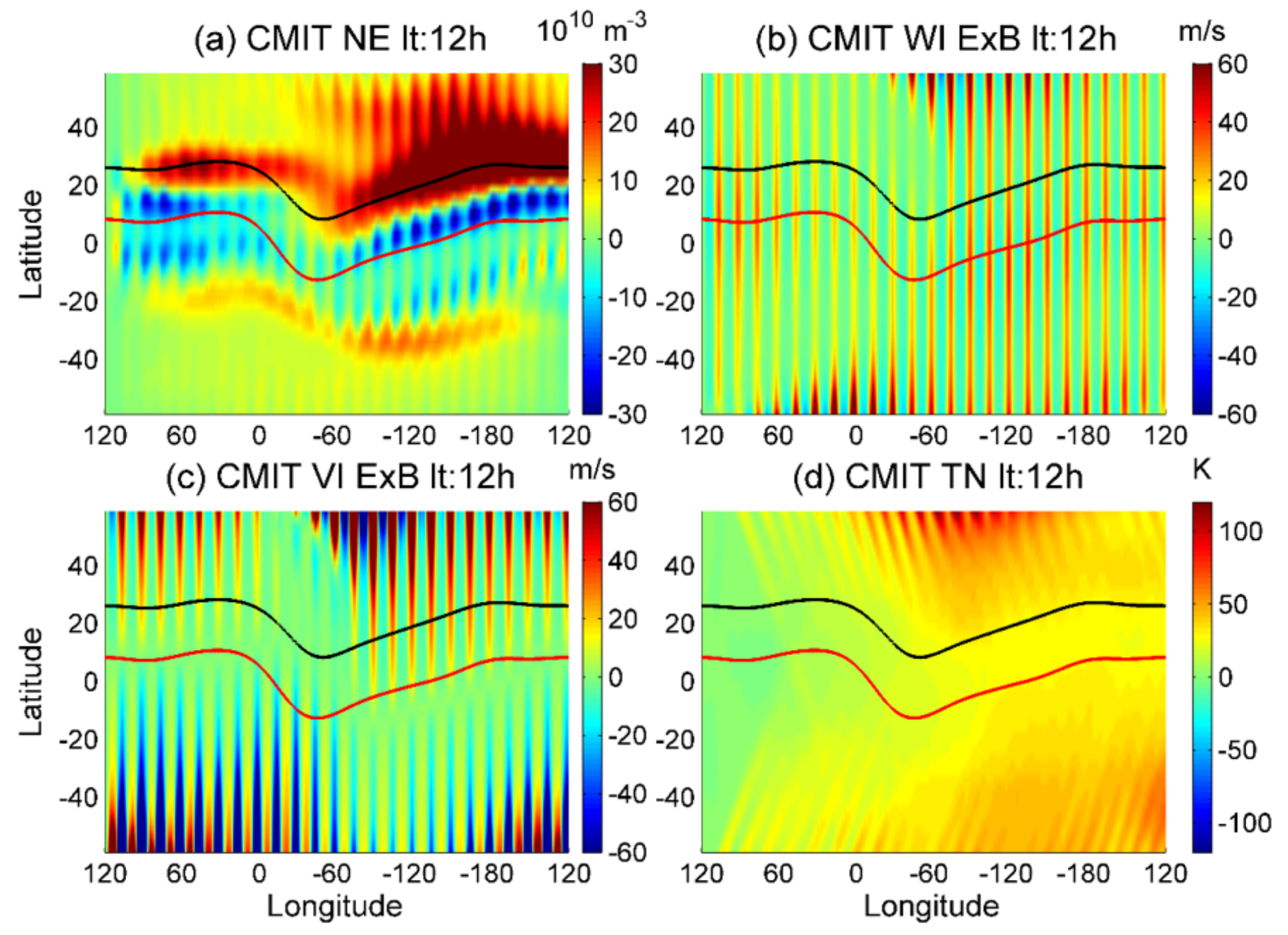

Figure 4

Similar to Figure 2, but for (a) electron density (NE), (b) vertical plasma velocity (WI ExB), (c) meridional plasma velocity (VI ExB), and (d) neutral temperature (TN) responses. The density is given in $1010 \mathrm{~m}-3$. The plasma velocity is given in $\mathrm{m} / \mathrm{s}$. The temperature is given in $\mathrm{K}$. The pressure level is $2.875(\sim 315 \mathrm{~km})$.

\section{Supplementary Files}

This is a list of supplementary files associated with this preprint. Click to download.

- graphicalabstractimage.png 